\title{
The Research on the Complementarity and Competitiveness of Yunnan and India Trade under the Belt and Road (B\&R)
}

\author{
Yingdong Geng \\ Yunnan Art University Wenhua College, Kunming, China
}

Keywords: The Belt And Road (b\&r); Trade Between Yunnan And India; Revealed Comparative Advantage; Trade Complementary Index.

\begin{abstract}
In recent years, with the development strategy of Belt and Road, the study of regional economic cooperation between China and South Asia has become a new focus for the study of international and regional economic cooperation. Under the proposal of "Building Yunnan Province into a radiation-oriented center to South Asia and Southeast Asia", India has become the fastest growing trading partners with Yunnan which brings new developments and challenges to each other. This paper analyzes the bilateral trade between Yunnan and India by introducing the Revealed Comparative Advantage and Trade Complementary Index. On the basis of the analysis we learn that Yunnan-India primary products exports share different comparative advantages in the third party market and the products with the comparative advantages varies significantly. Besides, Yunnan-India trade enjoys the complementarity but the recent degree of complementarity is declining. Finally, the potential of enhancing the Yunnan-India cooperation has been explored and the relevant advises on further improvement has been proposed.
\end{abstract}

\section{Introduction}

Yunnan, which has a special geographical advantage and strategic position, has had frequent business dealings with India since ancient times. At the 19th meeting of the National People's Congress in 2017, the "Belt and Road" initiative has reaffirmed its adherence to the principle of "sharing, building and sharing". In the contemporary era, the promotion of the "Belt and Road" strategy will push the trade cooperation between China and South Asia into a new stage, the cooperation between Yunnan and India has opened a new page. India is the fastest growing country among Yunnan's trading partners in more than 130 countries and regions. Yunnan's trade with India increased from $\$ 0.58$ billion to \$765 million from 2002 to 2015, with 13 times over 13 years and an average annual growth rate of 21.9 percent. In this paper, the four-digit commodity classified by SITC is used as the index of RCA and TCI, and the comparative advantage index and complementary index are used to conduct empirical research on the trade of Yunnan and India.

\section{Yunnan and India Trade status quo}

India is South Asia's the fastest growing economy country and Yunnan's largest trading partner in South Asia. In 2000, the total trade volume between Yunnan and India of Goods trade amounted to $\$ 4608$ million. In 2008, it expanded to $\$ 581.79$ million. In 2009, it was affected by the global financial crisis, and the trade volume decreased to $\$ 379.26$ million. The bilateral economic trade volume increased sharply in 2015, to $\$ 765 \mathrm{~m}$.In 2015, Yunnan's total exports to India amounted to \$534.2 million, up 21.17 times from 2005, and Yunnan's total imports from India amounted to \$2308 million, nearly 10 times the increase in 2005.

\section{Revealed Comparative Advantages (RCA) analysis of Yunnan India trade}

Balassa Revealed Comparative Advantage (RCA), which measures a specific product's share in the country's total exports relative to a share of this product in the world trade, is put forward by 
Balassa(1989). It is widely used by international organizations such as the World Bank to measure the competitive strength and professionalism of products, is to be used.

$$
\text { RCAxik= }(\mathrm{Xik} / \mathrm{Xt}) /(\mathrm{Wxk} / \mathrm{Wxt})
$$

Here Xik is export by country i of Product k. Xt is total amount of global exports of country t, Wxk is the total global exports of country $\mathrm{i}$ and Wxt is total amount of global exports.

When RCAxik is more than 1 , it indicates economy $\mathrm{i}$ has comparative advantage in product $\mathrm{k}$ in the world, and when RCAxik is less than 1, it shows economy i has no comparative advantage in product $\mathrm{k}$ in the world. To be specific, if RCAxik is more than 2.5, this economy has very strong competitiveness in product $\mathrm{k}$ in the world; if RCAxik is between 2.5 and 1.25, this economy has strong competitiveness in product $\mathrm{k}$ in the world; if RCAxik is between 1.25 and 0.8 , this economy has competitiveness in product $\mathrm{k}$ in the world [1] [p.81].

In terms of primary products, it can be seen from the table 1 that the export products of Yunnan and India are competitive in the third-party market. From the classification of primary products, Yunnan and India are not the same.SITC-0 (Food and Live Animal), the RAC of both Yunnan and India is more than 1 in decade. It shows that Yunnan and India has comparative advantage in this kind of product in the world. The RCA of Yunnan was larger than India from 2005 to 2015. It shows that Yunnan has more advantage in the world market in food and activity products. India's RCA index has fallen sharply, from 1.53 in 2005 to 1.04 in 2015, indicating that India's commodities have seen a decline in world market dominance.SITC-1(Beverage Tobacco Machinery), it shows that Yunnan province has absolute comparative advantage, The RCA reached 7.24 in 2015, while India is only 0.48, far less than Yunnan.SITC-2(Non-edible raw materials (excluding fuel)), it shows that India has absolute comparative advantage, The RCA reached 2.32 in 2005, while there was a decline in 2015, but it still has moderate comparative advantage than Yunnan.SITC-3(Fossil fuels, lubricants and related materials), India has a medium comparative advantage, while Yunnan has less than 0.8 in the RCA index, which does not have a comparative advantage.SITC-4(Vegetable oil, fat and wax), the RAC of Yunnan was less than 0.1 in decade, with a serious lack of comparative advantage. While the RCA of India is trending down and is less than 0.8 in 2015, with no comparative advantage (see table 1, 2).In terms of manufactured goods, SITC-5(Chemical products and related products not specified) and SITC-6(Manufactured goods mainly classified by raw materials), Yunnan has both comparative advantages in the two categories and the RCA is more than 2. SITC-6(Manufactured goods classified by raw materials), Yunnan and India both have comparative advantages, and the RCA of India is more than Yunnan in 2015. SITC-7(Machinery and transport equipment), Yunnan and India's RCA are both less than 0.8, indicating that Yunnan and India have no comparative advantage.SITC-8(Miscellaneous Products), Yunnan has no comparative advantage until 2009 and has a stronger comparative advantage by 2010, while India has a strong comparative advantage. SITC-9(Other goods and transactions not classified), Yunnan and India's RCA are both less than 0.8 with no comparative advantage (see table 1, 2).

Table1 The RCA index of Yunnan

\begin{tabular}{|c|c|c|c|c|c|c|c|c|c|c|c|}
\hline SITC Code & 2005 & 2006 & 2007 & 2008 & 2009 & 2010 & 2011 & 2012 & 2013 & 2014 & 2015 \\
\hline SITC-0 & 1.82 & 1.77 & 1.63 & 1.69 & 1.91 & 1.83 & 1.82 & 1.77 & 1.68 & 1.78 & 1.81 \\
\hline SITC-1 & 8.30 & 7.52 & 6.56 & 7.52 & 8.33 & 6.59 & 7.11 & 7.89 & 8.12 & 6.98 & 7.24 \\
\hline SITC-2 & 0.69 & 0.42 & 0.31 & 0.40 & 0.57 & 0.27 & 0.25 & 0.33 & 0.41 & 0.25 & 0.26 \\
\hline SITC-3 & 0.25 & 0.24 & 0.32 & 0.33 & 0.47 & 0.36 & 0.33 & 0.37 & 0.45 & 0.49 & 0.48 \\
\hline SITC-4 & 0.04 & 0.02 & 0.02 & 0.01 & 0.05 & 0.01 & 0.02 & 0.04 & 0.01 & 0.04 & 0.03 \\
\hline SITC-5 & 2.57 & 2.16 & 2.85 & 4.00 & 2.51 & 2.45 & 3.01 & 2.89 & 2.76 & 2.77 & 2.65 \\
\hline SITC-6 & 2.60 & 2.94 & 2.53 & 1.54 & 1.63 & 1.77 & 1.78 & 1.97 & 1.94 & 2.01 & 2.13 \\
\hline SITC-7 & 0.21 & 0.23 & 0.23 & 0.33 & 0.36 & 0.36 & 0.28 & 0.26 & 0.30 & 0.21 & 0.25 \\
\hline SITC-8 & 0.49 & 0.37 & 0.36 & 0.42 & 0.92 & 1.83 & 1.77 & 1.32 & 0.99 & 1.52 & 1.28 \\
\hline SITC-9 & 0.41 & 1.12 & 0.69 & 0.05 & 0.00 & 0.00 & 0.00 & 0.12 & 0.41 & 0.00 & 0.08 \\
\hline
\end{tabular}

Source: Calculated from Kunming Customs data 
Table2 The RCA index of India

\begin{tabular}{|c|c|c|c|c|c|c|c|c|c|c|c|}
\hline SITC Code & 2005 & 2006 & 2007 & 2008 & 2009 & 2010 & 2011 & 2012 & 2013 & 2014 & 2015 \\
\hline SITC-0 & 1.53 & 1.55 & 1.57 & 1.63 & 1.08 & 1.05 & 1.11 & 1.08 & 1.15 & 1.05 & 1.04 \\
\hline SITC-1 & 0.41 & 0.44 & 0.44 & 0.56 & 0.64 & 0.52 & 0.47 & 0.46 & 0.51 & 0.51 & 0.48 \\
\hline SITC-2 & 2.32 & 2.06 & 2.09 & 1.88 & 1.64 & 1.05 & 1.23 & 1.32 & 1.11 & 1.58 & 1.69 \\
\hline SITC-3 & 0.84 & 1.09 & 1.28 & 1.12 & 1.06 & 1.09 & 1.22 & 1.43 & 1.52 & 1.40 & 1.55 \\
\hline SITC-4 & 0.89 & 0.73 & 0.67 & 0.61 & 0.63 & 0.58 & 0.66 & 0.61 & 0.57 & 0.55 & 0.64 \\
\hline SITC-5 & 1.07 & 1.13 & 1.05 & 1.07 & 0.91 & 0.95 & 0.88 & 0.93 & 1.02 & 1.11 & 0.97 \\
\hline SITC-6 & 2.43 & 2.16 & 2.04 & 1.99 & 1.96 & 2.38 & 2.10 & 2.06 & 2.23 & 2.18 & 2.36 \\
\hline SITC-7 & 0.28 & 0.29 & 0.30 & 0.39 & 0.44 & 0.45 & 0.38 & 0.43 & 0.29 & 0.34 & 0.42 \\
\hline SITC-8 & 1.46 & 1.46 & 1.31 & 1.16 & 1.56 & 1.55 & 1.67 & 1.78 & 1.62 & 1.53 & 1.82 \\
\hline SITC-9 & 0.30 & 0.25 & 0.28 & 0.35 & 0.80 & 0.33 & 0.76 & 0.67 & 0.51 & 0.32 & 0.21 \\
\hline
\end{tabular}

Source: Calculated from United Nations commodity trade statistics database data.

\section{The Trade Complementarity Index (TCI) analysis of Yunnan India trade}

Although the exports of Yunnan and India have a certain competitive, because of the different resources endowment makes the product structure have great differences. To a certain extent, the product differences also explain the bilateral trade between Yunnan and India is complementary. This paper uses the Trade Complementarity Index to analyze. This section introduced by Peter Drysdale (1967) proposed by the trade Complementarity index analysis of the relevance of the export structure and India imports structure in Yunnan province, and use to measure the overall level of trade and the compact degree of trade complementary relationship. The calculation formula is:

$$
\begin{array}{r}
\text { TCIij= } \sum[\text { TCIijk } \times(\mathrm{Wk} / \mathrm{Wt})] \\
\text { TCIijk=RCAxik } \times \text { RCAmjk } \\
\text { RCAmjk=(Mjk/Mt)/(Wmk/Wmt })
\end{array}
$$

RCAxik represents the comparative advantage of the export of k products in country $i$, see the formula (1). RCAmjk represents the import of k products in $\mathrm{j}$ country is Comparative disadvantage. Mjk is the import amount of $\mathrm{k}$ in $\mathrm{j}$ country, Mt is the total import amount of the country $\mathrm{j}$, and Wmk represents the total value of the world's k merchandise imports, and Wmt represents the total amount of world imports. TCIijk represents the trade complementarity index between country $\mathrm{i}$ and $\mathrm{j}$ of commodities $\mathrm{k}$, and TCIij represents the comprehensive trade complementarity index of country $\mathrm{i}$ and $\mathrm{j}$, and $\mathrm{Wk}$ is the total value of world trade in $\mathrm{k}$ commodities, Wt is the world trade volume. If TCIij $>1$, it shows that the two countries have stronger trade complementarities. If $0.5<\mathrm{TCIij}<1$, it shows that the two countries have strong trade complementarities. It shows the trade complementarity between the two countries is not obvious [2] [p.40].

Table 3 The comprehensive trade complementarity index of Yunnan exports and India imports

\begin{tabular}{|c|c|c|c|c|c|c|c|c|c|c|c|}
\hline Year & 2005 & 2006 & 2007 & 2008 & 2009 & 2010 & 2011 & 2012 & 2013 & 2014 & 2015 \\
\hline $\begin{array}{c}\text { Comprehensive trade } \\
\text { complementarity index }\end{array}$ & 0.91 & 0.86 & 0.89 & 0.86 & 0.80 & 0.81 & 0.85 & 0.88 & 0.82 & 0.80 & 0.84 \\
\hline
\end{tabular}

Source: Calculated from United Nations commodity trade statistics database data and Kunming Customs data.

From table 3, the complementary index of Yunnan and India is less than 1 but also exceeds 0.8, indicating that there is certain trade complementarity between them. Overall, the export of Yunnan and the import trade of India have certain trade complementarity level. But the data also shows that 
the trade complementarity index of Yunnan and India is declining. In order to further understand Yunnan's export and India's import trade complementarity in specific product categories, according to the customs data from year 2005 to 2015 that based on SITC ten categories of products, the trade complementarity between Yunnan export and Indian import classification products concentrated relatively from Table 4.

In Primary products, Yunnan's export in SITC-0 (Food and Live Animal), SITC-1 (Beverages and Tobacco), SITC-2 (non-food raw materials (excluding fuel)) and SITC-3 (fossil fuel, lubricating oil and related raw materials) in 2005 has some trade complementarity with Indian imports. In 2015, the SITC-3 (fossil fuel, lubricating oil and related raw materials) is still complementary, others are declining. In industrial products, SITC-5 (unlisted chemical products and related products) and SITC-6 (manufactured products mainly classified by raw materials) have strong complementarity, with each complementary index exceeding 1.

Table 4 The trade complementarity index of the classification products from Yunnan 's export and India's import

\begin{tabular}{|c|c|c|c|c|c|c|c|c|c|c|c|}
\hline SITC Code & 2005 & 2006 & 2007 & 2008 & 2009 & 2010 & 2011 & 2012 & 2013 & 2014 & 2015 \\
\hline SITC-0 & 0.52 & 0.49 & 0.50 & 0.35 & 0.57 & 0.44 & 0.44 & 0.48 & 0.52 & 0.49 & 0.51 \\
\hline SITC-1 & 0.63 & 0.58 & 0.50 & 0.56 & 0.54 & 0.38 & 0.51 & 0.56 & 0.50 & 0.60 & 0.58 \\
\hline SITC-2 & 0.97 & 0.71 & 0.46 & 0.49 & 0.66 & 0.40 & 0.44 & 0.51 & 0.40 & 0.52 & 0.47 \\
\hline SITC-3 & 0.60 & 0.56 & 0.76 & 0.69 & 1.02 & 0.66 & 0.61 & 0.77 & 0.64 & 0.68 & 0.71 \\
\hline SITC-4 & 0.21 & 0.09 & 0.06 & 0.02 & 0.18 & 0.08 & 0.03 & 0.06 & 0.05 & 0.02 & 0.04 \\
\hline SITC-5 & 2.28 & 1.85 & 2.49 & 4.08 & 2.16 & 2.33 & 2.45 & 3.78 & 3.62 & 4.11 & 3.25 \\
\hline SITC-6 & 3.10 & 2.66 & 2.40 & 1.40 & 1.90 & 2.39 & 1.89 & 1.78 & 2.01 & 1.56 & 1.46 \\
\hline SITC-7 & 0.11 & 0.14 & 0.14 & 0.20 & 0.23 & 0.19 & 0.13 & 0.25 & 0.28 & 0.10 & 0.14 \\
\hline SITC-8 & 0.15 & 0.12 & 0.12 & 0.10 & 0.29 & 0.43 & 0.31 & 0.20 & 0.11 & 0.15 & 0.13 \\
\hline SITC-9 & 1.16 & 2.49 & 1.63 & 0.12 & 0.00 & 0.00 & 0.00 & 0.32 & 0.57 & 0.11 & 0.00 \\
\hline
\end{tabular}

Source: Calculated from United Nations commodity trade statistics database data and Kunming Customs data.

\section{Conclusions and policy recommendations}

According to the dominant comparative advantage index, first of all, Yunnan should pay high attention to the development of the first industry and improve the quality of products for SITC-1 (Beverages and Tobacco) and SITC-0 (Food and Live Animal), so as to make Yunnan characteristic agricultural products more competitive. Secondly, Yunnan has a strong competitive advantage in Chemical products and related products which contain Yunnan province's top 10 export products, such as fertilizer. The chemical industry dominated by phosphorous chemical industry is the pillar industry of Yunnan mining industry. Yunnan should pay attention to improve the quality of fertilizer and increase the added value of fertilizer. The nonferrous metals of Yunnan such as tin, lead, aluminum, zinc have also been advantageous industries and have a great demand in the Indian market. But in Yunnan's foreign trade, chemical industry is low added value, lack of competitiveness, short of leading product, which is difficult to be reverse fundamentally. In order to give a full play to the superiority of the chemical industry, Yunnan should transform high-tech chemical enterprises, and combine the phosphorus, electricity and chemical development, take as the guidance of market to strengthen energy saving reconstruction. Through the trade complementarity index, Yunnan-India should strengthen the cooperation in mineral exploration and development. As "non-ferrous metal kingdom", Yunnan has the outstanding advantages in the mineral exploration. The iron, steel and non-ferrous metal enterprises in Yunnan should play their respective advantages, and leading to the cooperation pattern from commodity trade to minerals exploration and processing direction. 
Secondly, India is rich in pearls, precious and semi-precious stones, whereas Yunnan has no advantage in such products. In terms of gold and other precious metals, Yunnan is better than India. With the help of geography superiority and advantages of precious metals and manufactured goods, Yunnan should joint venture with India to open India's market and also to activate the new great cooperation energy of Yunnan even China-India or SAARC.

\section{References}

[1] Balassa. The theory of Economic Integration (1965) [M].London: Allen and Unwin,1962,67.

[2] Marcella, EnricoAn. Empirical assessment of opening up, trade specialization and FDI in China and India [J]. Business and Economics, 2011(8). 